\title{
Geoquímica dos diques máficos de Brumado, porção sudeste do Bloco Gavião, Bahia, Brasil
}

\author{
Geochemistry of mafic dykes of Brumado, southeastern portion of Gavião Block, Bahia, Brazil
}

\author{
Lílian Mercês Pereira Varjão ${ }^{1}$ (D), Angela Beatriz de Menezes Leal ${ }^{1}$ (D) \\ ${ }^{1}$ Universidade Federal da Bahia - UFBA, Instituto de Geociências, Departamento de Geologia, Programa de Pós-Graduação \\ em Geologia, Núcleo de Geologia Básica, Rua Barão de Jeremoabo, s/n., CEP 40.170-020, Campus Universitário de Ondina, \\ Salvador, BA, BR (lilian.merces@yahoo.com; angelab@ufba.br)
}

Recebido em 26 de março de 2018; aceito em 9 de agosto de 2019

\begin{abstract}
Resumo
No sudoeste do estado da Bahia, entre as cidades de Brumado e Caetité e mais a norte próximo às cidades de Tanque Novo, Paramirim, Botuporã, Macaúbas, Novo Horizonte e Ibitiara, ocorrem diques máficos formados em ambiente intraplaca. São toleítos continentais apresentando valores de índice de diferenciação em magnésio (mg\#) entre 0,25 e 0,45 , indicativos de líquidos magmáticos evoluídos. Plagioclásio e augita predominaram no processo magmático evolutivo, cujos diagramas não mostram alterações significativas por processos secundários. Os diques máficos originaram-se de fonte pouco heterogênea tipo Enriched Mid-Ocean Ridge Basalt (E-MORB), provavelmente com leve contribuição de fluidos tipo Ocean Island Basalt (OIB). Os dados geoquímicos sugerem influência significativa da crosta continental inferior na origem da fonte mantélica, não havendo sinais de importante contribuição sedimentar.
\end{abstract}

Palavras-chave: Litogeoquímica; Petrografia; Diques máficos; Bloco Gavião; Manto.

\begin{abstract}
In the southwest of the state of Bahia, between the cities of Brumado and Caetité and further north near the cities of Tanque Novo, Paramirim, Botuporã, Macaúbas, Novo Horizonte and Ibitiara, there are mafic dykes formed in an intraplate environment. These continental tholeiites with magnesium differentiation index values (mg\#) between 0.25 to 0.45 , indicative of evolved magmatic liquids. Plagioclase and augite are predominant phases in the magmatic evolutionary process, whose diagrams show no significant alterations by secondary processes. The mafic dikes originated from a somewhat heterogeneous Enriched Mid-Ocean Ridge Basalt (E-MORB) source, probably with a slight contribution of Ocean Island Basalt (OIB) fluids. The geochemical data suggest a significant influence of the inferior continental crust on the origin of the mantle source, with no signs of significant sedimentary contribution.
\end{abstract}

Keywords: Lithogeochemistry; Petrography; Mafic dykes; Gavião Block; Mantle. 


\section{INTRODUÇÃO}

O estudo das rochas máficas e ultramáficas, apresentadas sob a forma de diques e sills, é de grande importância para o entendimento dos processos geodinâmicos e, consequentemente, na reconstituição da história geológica de uma determinada região. Diversas pesquisas realizadas sobre diques máficos evidenciaram a importância e o porquê de se estudar esse magmatismo basáltico fissural (e.g., Halls, 1982; Oliveira e Montes, 1984; Windley, 1984; Halls e Fahrig, 1987). No Brasil, estudos têm se efetuado em áreas cratônicas (e.g., Menezes, 1992; Corrêa-Gomes et al., 1996; Menezes Leal, 1997; Corrêa da Costa, 2003; Corrêa da Costa et al., 2006, 2009; Menezes Leal et al., 2012; Girardi et al., 2011, 2013, 2017; Trindade Netto et al., 2016; Pinheiro Amorim, 2017; Teixeira et al., 2019; Giovanardi et al., 2019), pois essas manifestações de magmatismo preenchem fraturas que revelam condições distensivas na crosta, fornecem indicações das condições reológicas do meio, são alimentadoras e condutoras de ascensão magmática do manto para a crosta, permitem estabelecer as condições que operavam em ambientes intraplaca ou nas margens de placas continentais e contribuem para o entendimento do magmatismo basáltico fissural na história da Terra.

Na porção sudeste do Bloco Gavião (BG), região sudoeste do estado da Bahia, nas circunvizinhanças das cidades de Brumado, e mais a norte próximo às cidades de Tanque Novo, Paramirim, Botuporã, Macaúbas, Novo Horizonte e Ibitiara, afloram diques máficos intrusivos nas rochas do embasamento arqueano. O presente trabalho visou apresentar e discutir os resultados de dados petrográficos (macro e microscópicos) e geoquímicos, por meio dos elementos maiores, traço e terras raras, objetivando contribuir na caracterização da origem dessas rochas.

\section{CONTEXTO GEOLÓGICO}

Os diques máficos intrudem rochas ortoderivadas na porção sudoeste do BG, sul do Cráton do São Francisco (Figura 1). O BG expõe um dos mais preservados segmentos de crosta arqueana da Plataforma Sul-Americana, de idade 3,2-3,4 Ga (U-Pb SHRIMP) (Martin et al., 1991; Marinho, 1991; Nutman e Cordani, 1993; Bastos Leal et al., 1998). É constituído de terrenos graníticos-gnáissicos com variáveis graus de migmatização, formado por tonalitos-trondhjemitos, granodioritos (suítes TTG) e granitos metamorfizados na fácies anfibolito. Seu limite oeste é marcado por sistema de cavalgamento dos terrenos graníticos-gnáissicos-migmatíticos arqueanos sobre os sedimentos mesoproterozoicos do Supergrupo Espinhaço; o limite leste é definido por falhamentos de empurrão resultantes da tectônica que transportou os terrenos granulíticos do Bloco Jequié sobre as rochas do greenstone belt Contendas Mirantes; o limite norte é parcialmente coberto por rochas sedimentares representadas pelos Grupos Paraguaçu e Chapada Diamantina (Supergrupo Espinhaço) e Una (Supergrupo São Francisco); e o limite sul é representado pelo contato com a faixa móvel Araçuaí formados durante o Brasiliano (Bastos Leal, 1998; Bastos Leal et al., 2003). A Figura 2 mostra o mapa geológico simplificado da área de estudo, destacando as principais unidades geológicas da região (CPRM/CBPM, 2003).

A evolução do BG é marcada pela formação de núcleos granitoides a partir de vários episódios de plutonismo TTG com idades variando entre 3,15 e 3,42 Ga (métodos $\mathrm{Rb} / \mathrm{Sr}$, $\mathrm{Pb}-\mathrm{Pb}$ rocha total e monozircão e $\mathrm{U}-\mathrm{Pb}$ ), representado pelos maciços de Sete Voltas, Boa Vista/Mata Verde, Bernarda, Aracatu e Lagoa da Macambira (Santos-Pinto, 1996; Bastos Leal, 1998; Bastos Leal et al., 1998; Barbosa e Sabaté, 2004; Barbosa et al., 2012). Entre 3,1 e 2,5 Ga houve a formação dos greenstone belts de Umburanas (Cunha e Fróes, 1994; Menezes Leal et al., 2016) e Contendas Mirante (Marinho, 1991; Arcanjo et al., 2000), e por intrusão de granitoides (Malhada de Pedras e Lagoa da Macambira) há cerca de 2,8 e 2,5 Ga (método Rb-Sr) (Barbosa et al., 2012). Durante o Paleoproterozoico (entre 2,0 e 1,8 Ga - método Rb-Sr), o $\mathrm{BG}$ foi deformado e metamorfizado regionalmente e intrudido por granitos de diferentes composições nas unidades arqueanas vulcanossedimentares e nos terrenos gnáissicos-migmatíticos (Menezes Leal et al., 2005; Barbosa et al., 2012). Bastos Leal et al. (1998) sugeriram, por meio de dados isotópicos de $\mathrm{Sr}$ e $\mathrm{Nd}$, que esses granitos foram formados por meio da reciclagem de crosta continental primitiva durante a evolução da orogenia Paleoproterozoica. Por fim, durante o Meso e o Neoproterozoico, atividades tectono-metamórficas promoveram a intrusão de diques máficos e o rejuvenescimento isotópico das idades $\mathrm{K}-\mathrm{Ar}$ e Rb-Sr (Bastos Leal, 1998; Bastos Leal et al., 1998).

Os diques máficos da região de Brumado não foram datados. No entanto, Guimarães et al. (2005) obtiveram idade em torno de $1.496 \pm 3.2 \mathrm{Ma}$ nos gabros intrusivos em rochas metassedimentares da Chapada Diamantina, pelo método U-Pb, Laser Ablation, em zircão. Silveira et al. (2013) obtiveram idade U-Pb (ID-TIMS) de $1.501 \pm 9.1 \mathrm{Ma}$ em badeleita em dique máfico intrusivo nos quartzitos na Formação Mangabeira. Possivelmente, os diques da presente pesquisa são cronocorrelatos aos da Chapada Diamantina, por fazerem parte de um mesmo contexto tectônico de formação.

\section{GEOLOGIA LOCAL E CARACTERÍSTICAS PETROGRÁFICAS}

Os diques máficos preenchem fraturas distensivas de direção WNW-ESE e encontram-se encaixados em rochas graníticas, gnáissicas e migmatíticas do embasamento arqueano do BG e 
no Supergrupo Espinhaço (Brito, 2005, 2008; Pereira, 2007; Pereira Varjão, 2017; Pereira Varjão e Menezes Leal, 2017).

É comum a presença de blocos e matacões (Figura 3A). Por outro lado, o núcleo dessas rochas encontra-se preservado dessa deformação plástica, apresentando crescimento de cristais de plagioclásio, em forma de ripas, sem orientação evidente (Figura 3B).

Predomina a textura subofítica e, subordinadamente, a ofítica e intergranular (Figuras 4A e 4B). São constituídos de plagioclásio e augita compondo os minerais essenciais, seguidos de minerais opacos (magnetita e ilmenita), quartzo, zircão e apatita, como acessórios. Destacam-se em algumas amostras minerais de origem secundária como hornblenda, biotita, clorita, carbonato, mica branca, epídoto e esfeno, provenientes da desestabilização dos cristais de plagioclásio, piroxênio e minerais opacos formando a paragênese de alteração hidrotermal/deutérica.

\section{MÉTODOS ANALÍTICOS}

Foram selecionadas 15 amostras para a obtenção das concentrações de elementos maiores e traço e dez amostras para determinação dos elementos terras raras. As análises foram realizadas nos Laboratórios de Fluorescência de Raios $\mathrm{X}$ e de Química e Plasma ICP-AES (Inductively Coupled Plasma-Atomic Emission Spectrometer), do Departamento de Mineralogia e Geotectônica do Instituto de Geociências
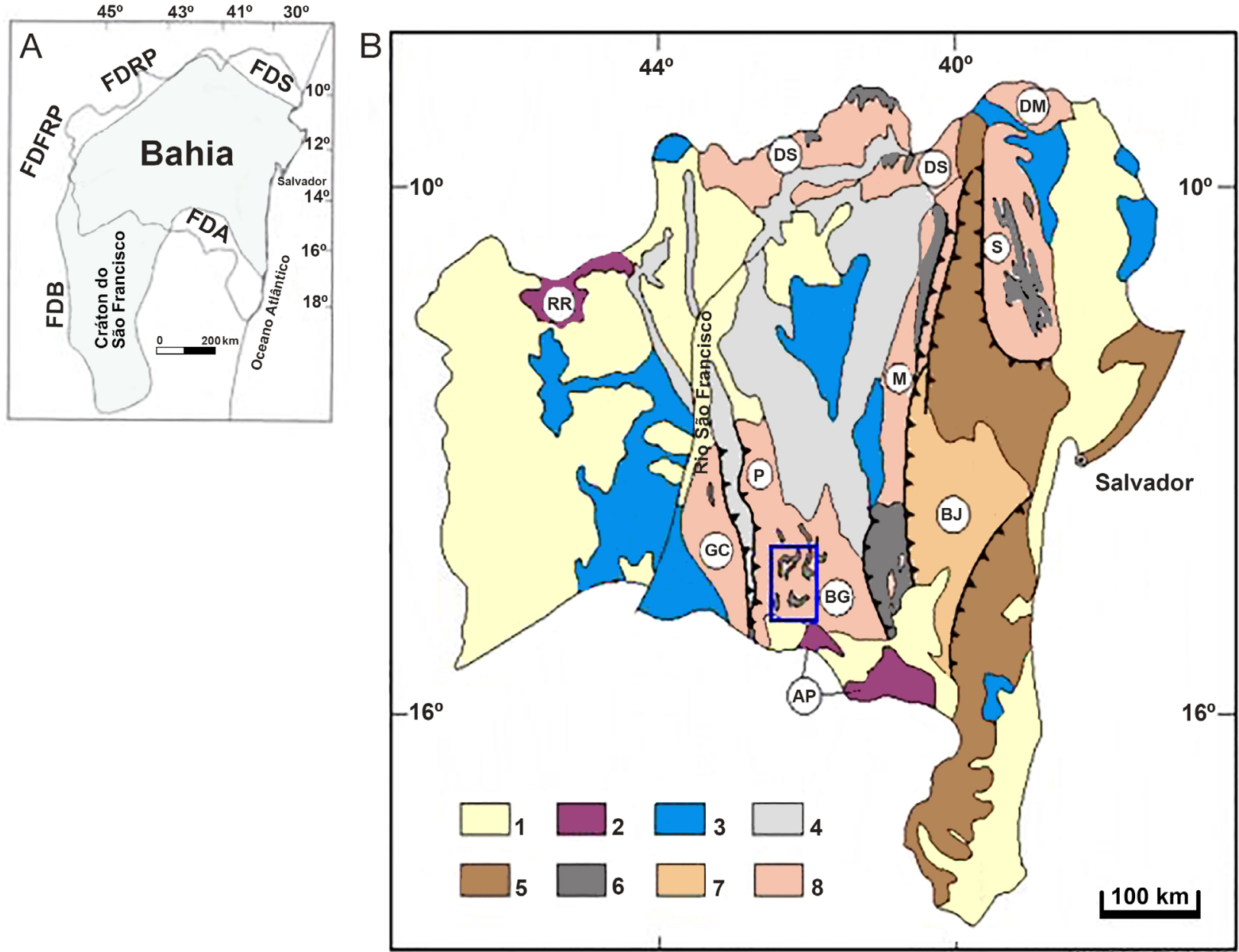

FDB: Faixa de Dobramento Brasília; FDA: Faixa de Dobramento Araçuaí; FDS: Faixa de Dobramento Sergipana; FDFRP: Faixa de Dobramento Formosa do Rio Preto; FDRP: Faixa de Dobramento Riacho do Pontal; 1: coberturas fanerozoicas; 2: faixas de dobramentos (AP: Araçuaí; DS: Sergipana; RR: Formosa do Rio Preto); 3: coberturas plataformais do Neoproterozoico (Supergrupo São Francisco); 4: coberturas plataformais do Mesoproterozoico (Supergrupo Espinhaço); 5: cinturões móveis do Paleoproterozoico; 6: Sequência Sedimentar e Metassedimentar do Arqueano; 7 e 8: Blocos Arqueanos (BJ: Bloco Jequié, BG: Bloco do Gavião; GC: Bloco Guanambi-Correntina; P: Bloco Paramirim; M: Bloco Mairi; S: Bloco Serrinha).

Figura 1. (A) Localização do Cráton do São Francisco e suas Faixas Marginais (modificado e adaptado de Cruz Filho et al., 1999); (B) esboço geológico e compartimentação geotectônica do estado da Bahia (modificado e adaptado de Barbosa e Dominguez, 1996). Retângulo azul representa a área de pesquisa. 


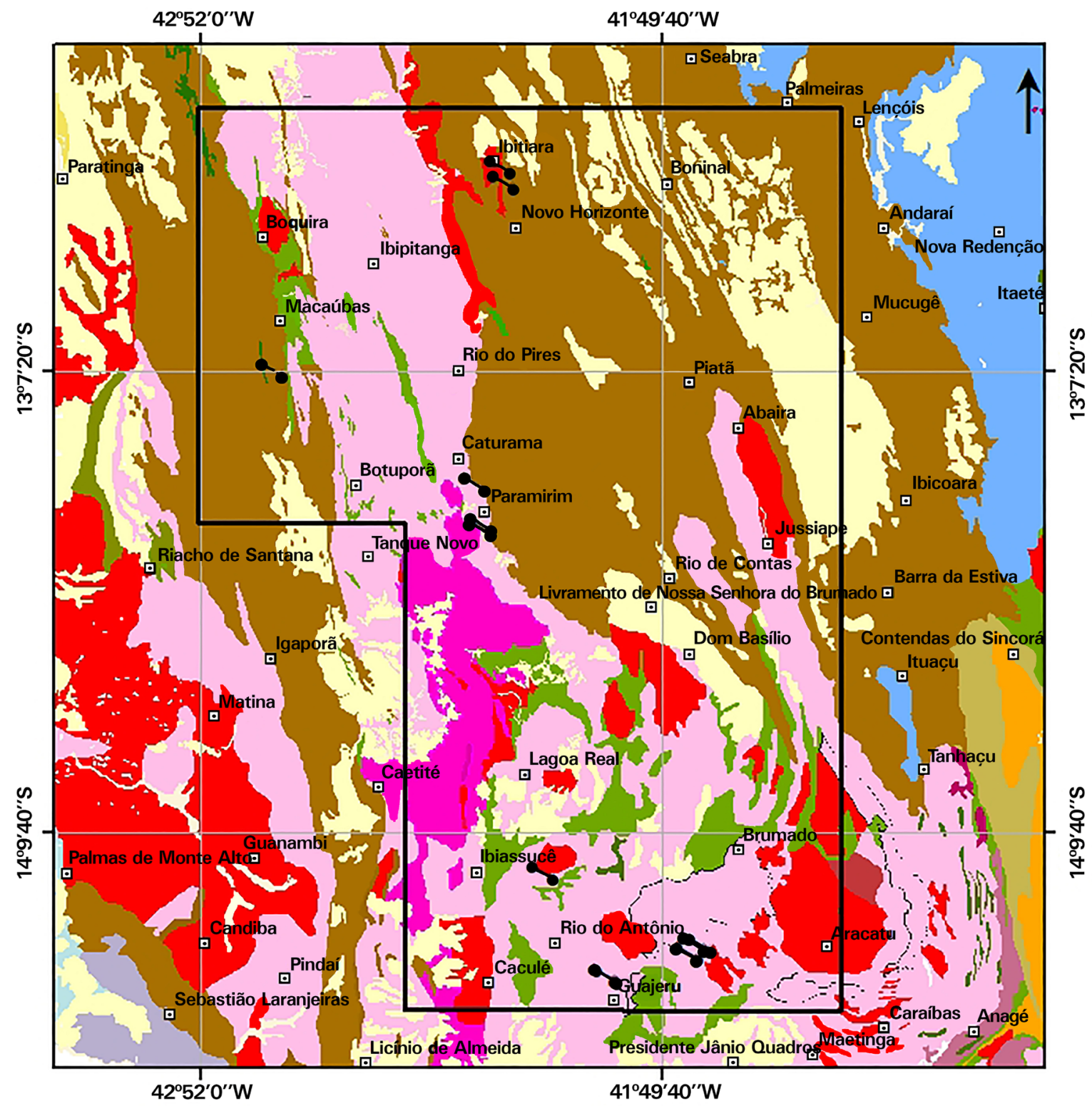

Coberturas detrito-lateríticas com concreções ferruginosas

Grupo São Francisco: Formação Bebedouro e Unidade Gabriel: calcarenitos, carbonatos e calcilutitos

Supergrupo Espinhaço: Formações Mangabeira, Fazendinha, Lagoa de Dentro, Açuruá,

Ouricuri do Ouro, Cabaclo, Tombador e Morro do Capéu

Sequências vulcanossedimentares

Suíte Intrusiva Lagoa Real: gnaisses e albititos

Granitoides estaterianos

Embasamento gnáissico migmatítico do Bloco Gavião
Pontos de diques máficos amostrados

๑ Cidades

|Área de pesquisa

Escala 1:1300.000

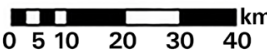

Fonte: modificado de CPRM/CBPM (2003).

Figura 2. Mapa geológico regional simplificado com a localização da área de estudo e a distribuição dos pontos de diques máficos amostrados neste trabalho. 
da Universidade de São Paulo (GMG-IGc/USP). Os valores obtidos e com os quais se construiu todos os diagramas apresentados foram considerados satisfatórios, mostrando boa correlação entre os elementos maiores e traço. As análises químicas dos elementos maiores, traço e terras raras estão apresentadas na Tabela $1 . \mathrm{O} \mathrm{Fe}_{2} \mathrm{O}_{3}$ foi determinado pela análise química como ferro total, e o $\mathrm{FeO}$ foi calculado assumindo a razão $\mathrm{Fe}_{2} \mathrm{O}_{3} / \mathrm{FeO}=0,15$. Os erros analíticos para os elementos maiores, traço e terras raras foram, respectivamente, de menos de $3 \%$ para os dois primeiros e \pm 3 ppm para o último.

\section{GEOQUÍMICA DE ROCHA TOTAL}

Para avaliar a possibilidade de mobilização de elementos químicos, foi testado, nos diques máficos de Brumado, um método originalmente proposto por Pearce (1968) e posteriormente adaptado por Beswick e Soucie (1978) e Beswick (1982) para interpretar trends de fracionamento de rochas que sofreram alteração hidrotermal ou metamórfica, denominado Molecular Proportion Ratios (MPR) ou Método de Razões em Proporções Moleculares. Observou-se nos diagramas que as razões entre elementos maiores das amostras estudadas não sofreram modificações por mobilidade dos elementos considerados (Figura 5). O diagrama da Figura 6 (Miyashiro, 1975) corrobora com a não mobilidade dos elementos $\mathrm{Na}_{2} \mathrm{O}$ e $\mathrm{K}_{2} \mathrm{O}$ durante os processos hidrotermais.

$\mathrm{O}$ diagrama AFM - $\mathrm{A}\left(\mathrm{Na}_{2} \mathrm{O}+\mathrm{K}_{2} \mathrm{O}\right), \mathrm{F}(\mathrm{FeOt}), \mathrm{M}$ $(\mathrm{MgO})$ - (Irvine e Baragar, 1971; Figura 7A) mostra que os litotipos estudados acompanham o trend da suíte toleítica do Hawaii (MacDonald e Katsura, 1964; Irvine e Baragar, 1971), apresentando caráter toleítico com leve enriquecimento de FeOt em relação ao $\mathrm{MgO}$, e no diagrama da Figura 7B
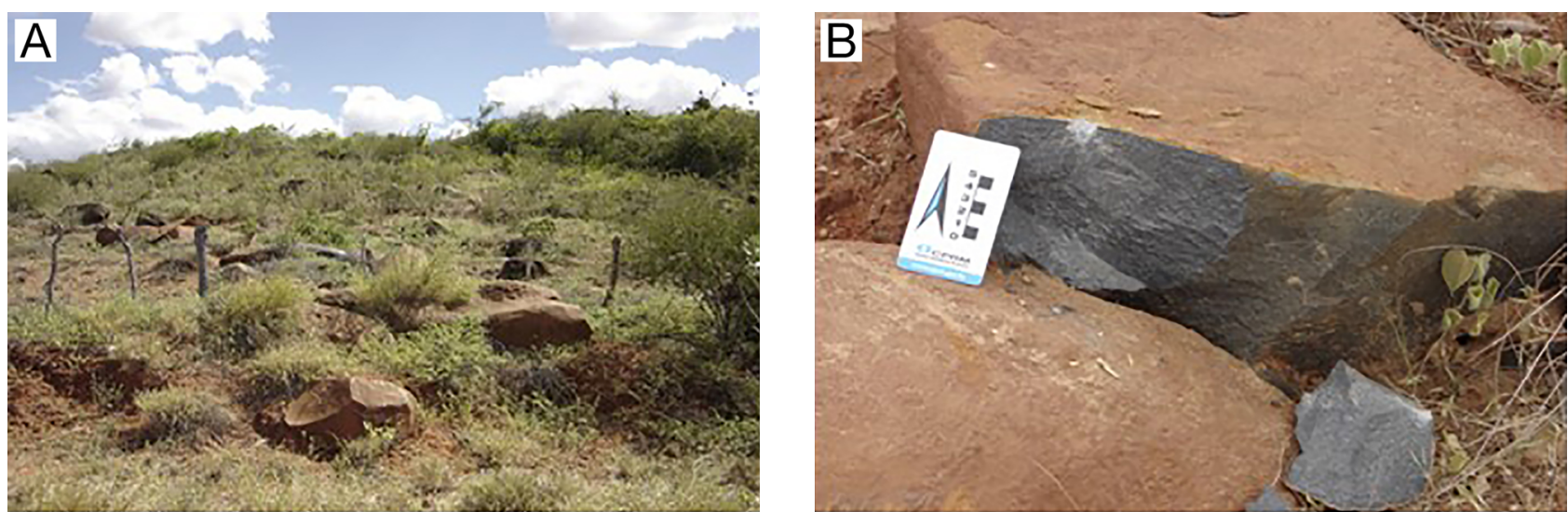

Figura 3. Fotografias de campo dos diques máficos. (A) Ocorrência dos diques máficos sob a forma de blocos e matacões alinhados segundo a direção preferencial WNW-ESE. Ponto BLV-03 (UTM 202464/8405152); (B) aspecto geral do dique máfico mostrando cor cinza e granulação fina. Ponto BLV-08 (UTM 179886/8396834).
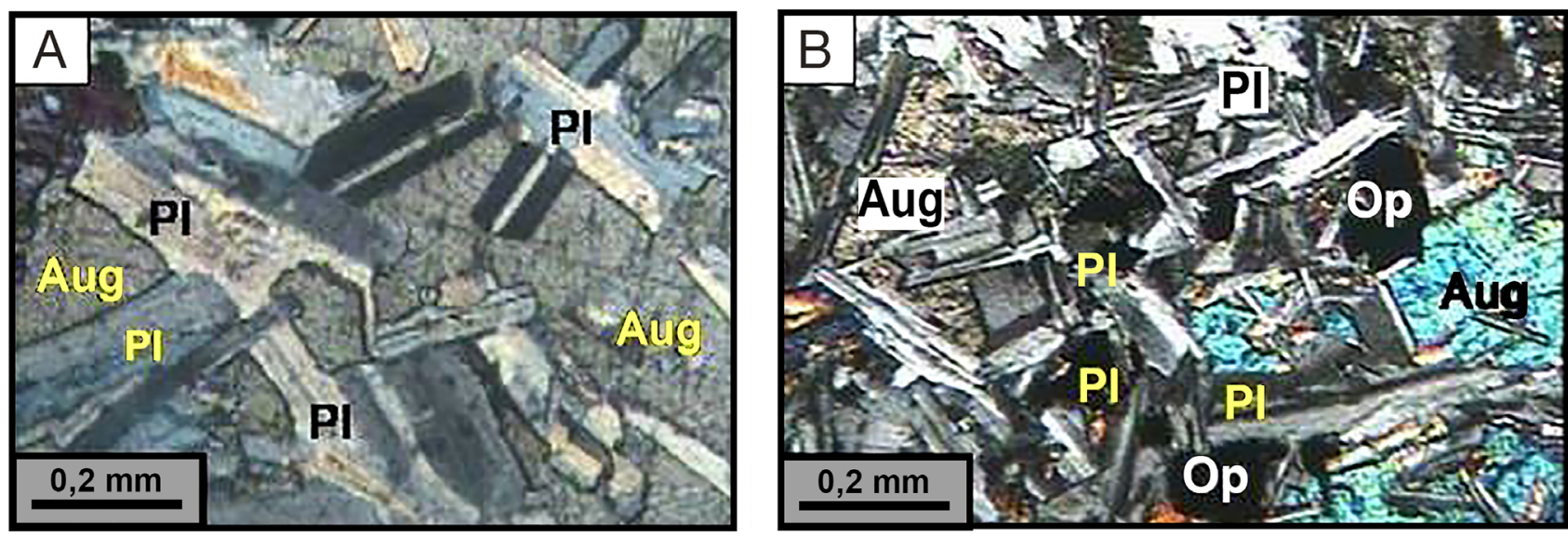

Pl: plagioclásio; Aug: augita; Op: mineral opaco.

Figura 4. Fotomicrografias dos diques máficos. (A) Cristais de plagioclásio subédricos englobando cristais de augita. Amostra BLV-01. Polarizadores cruzados; (B) aspecto geral da textura sub-ofítica e intergranular mostrando a geometria das ripas de plagioclásio. Amostra BLV-04. Polarizadores cruzados. Abreviações segundo Whitney e Evans (2010). 
(Le Bas et al., 1986), verifica-se que todas as amostras estudadas plotam no campo dos basaltos.

Os diques máficos constituem-se dominantemente por rochas básicas, com valores de $\mathrm{SiO}_{2}$ entre 46,99 e $50,27 \%$ e com 5,16 a $8,26 \%$ de $\mathrm{MgO}$. O teor de $\mathrm{mg \#}$ $[\mathrm{MgO} /(\mathrm{MgO}+\mathrm{FeOt})]$ varia de 0,25 a 0,45 . Tais valores são indicativos de líquidos basálticos evoluídos, pois magmas basálticos primitivos possuem valores $\mathrm{mg} \#$ entre $0,74 \mathrm{e}$ 0,80 (Jacques e Green, 1979; Takahashi e Kushiro, 1983).

De maneira geral, os diques máficos estudados apresentam, nos diagramas de variação (Figura 8), um aumento nas concentrações de $\mathrm{SiO}_{2} \mathrm{FeOt}, \mathrm{TiO}_{2}, \mathrm{~K}_{2} \mathrm{O}$ e $\mathrm{P}_{2} \mathrm{O}_{5}$ com o avanço da cristalização, ou seja, com a diminuição do $\mathrm{MgO}$. Esse comportamento sugere a atuação do processo de cristalização fracionada. $\mathrm{O} \mathrm{Na}_{2} \mathrm{O}$ apresenta comportamento aproximadamente constante, apesar de indicar um discreto aumento com a diferenciação. $\mathrm{Al}_{2} \mathrm{O}_{3} \mathrm{e} \mathrm{CaO}$ apresentam comportamentos equivalentes diminuindo sua concentração com o avanço da cristalização. Esse comportamento reflete a importância do plagioclásio e do clinopiroxênio no processo evolutivo.

Em relação aos elementos traço (Figura 9), verificou-se uma diminuição do elemento compatível Ni com o decréscimo de

Tabela 1. Análises químicas de elementos maiores e traço dos diques máficos de Brumado. mg\# = MgO/(MgO $+\mathrm{FeOt})$.

\begin{tabular}{|c|c|c|c|c|c|c|c|c|c|c|c|c|c|c|c|}
\hline Amostra & BLV-1 & BLV-2 & BLV-3 & BLV-4 & BLV-5 & BLV-6 & BLV-7 & BLV-8 & BLV-9 & BLV-12 & BLV-13 & BLV-14 & BLV-15 & BLV-16 & BLV-17 \\
\hline $\begin{array}{l}\text { Latitude / } \\
\text { Longitude }\end{array}$ & $\begin{array}{l}199285 / \\
8402432\end{array}$ & $\begin{array}{l}199595 / \\
8402866\end{array}$ & $\begin{array}{l}202464 / \\
8405152\end{array}$ & $\begin{array}{l}201079 / \\
8405388\end{array}$ & $\begin{array}{l}201075 / \\
8405380\end{array}$ & $\begin{array}{l}179287 / \\
8397198\end{array}$ & $\begin{array}{l}179573 / \\
8397034\end{array}$ & $\begin{array}{l}179886 / \\
8396834\end{array}$ & $\begin{array}{l}811525 / \\
8422800\end{array}$ & $\begin{array}{l}803068 / \\
8599004\end{array}$ & $\begin{array}{l}797550 / \\
8509118\end{array}$ & $\begin{array}{l}803942 / \\
8595098\end{array}$ & $\begin{array}{l}795892 / \\
8519932\end{array}$ & $\begin{array}{l}797558 / \\
8509882\end{array}$ & $\begin{array}{l}746962 / \\
8549048\end{array}$ \\
\hline$\overline{\mathrm{SiO}_{2}}$ & 46,99 & 48,51 & 50,27 & 47,66 & 47,30 & 47,74 & 47,96 & 47,91 & 47,91 & 47,27 & 47,96 & 48,87 & 47,91 & 47,77 & 47,68 \\
\hline $\mathrm{Al}_{2} \mathrm{O}_{3}$ & 11,84 & 12,57 & 14,34 & 14,13 & 13,80 & 14,65 & 15,12 & 16,73 & 14,35 & 18,19 & 14,70 & 13,00 & 14,54 & 14,23 & 13,56 \\
\hline FeOt & 17,61 & 16,44 & 12,44 & 13,69 & 14,00 & 11,77 & 11,86 & 11,14 & 12,34 & 10,38 & 11,34 & 14,96 & 11,33 & 11,53 & 13,93 \\
\hline $\mathrm{MgO}$ & 6,20 & 5,41 & 6,53 & 6,43 & 6,82 & 8,26 & 7,64 & 6,43 & 7,70 & 8,13 & 7,63 & 5,16 & 7,36 & 7,39 & 5,92 \\
\hline $\mathrm{CaO}$ & 9,41 & 9,31 & 10,14 & 9,95 & 11,58 & 11,57 & 11,14 & 11,41 & 11,29 & 10,59 & 10,99 & 9,08 & 10,69 & 10,80 & 9,87 \\
\hline $\mathrm{Na}_{2} \mathrm{O}$ & 2,26 & 2,42 & 2,53 & 2,76 & 2,39 & 2,17 & 2,25 & 2,44 & 2,24 & 2,50 & 2,16 & 1,82 & 2,29 & 2,25 & 2,43 \\
\hline $\mathrm{K}_{2} \mathrm{O}$ & 0,64 & 0,77 & 0,51 & 0,64 & 0,27 & 0,35 & 0,39 & 0,42 & 0,39 & 0,31 & 0,49 & 0,94 & 0,44 & 0,42 & 0,28 \\
\hline $\mathrm{TiO}_{2}$ & 3,04 & 2,68 & 1,53 & 2,92 & 2,06 & 1,60 & 1,72 & 1,63 & 1,79 & 1,24 & 1,57 & 2,42 & 1,60 & 1,65 & 2,76 \\
\hline $\mathrm{MnO}$ & 0,24 & 0,23 & 0,18 & 0,18 & 0,20 & 0,18 & 0,18 & 0,16 & 0,18 & 0,17 & 0,19 & 0,33 & 0,19 & 0,19 & 0,28 \\
\hline $\mathrm{P}_{2} \mathrm{O}_{5}$ & 0,24 & 0,28 & 0,18 & 0,35 & 0,15 & 0,17 & 0,23 & 0,21 & 0,32 & 0,10 & 0,19 & 0,27 & 0,19 & 0,20 & 0,38 \\
\hline $\mathrm{CO}_{2}$ & 0,04 & 0,03 & 0,03 & 0,03 & 0,02 & 0,02 & 0,04 & 0,03 & 0,04 & $\mathrm{ND}$ & ND & ND & ND & ND & ND \\
\hline LOI & 0,10 & 0,10 & 0,10 & 0,10 & 0,10 & 0,10 & 0,10 & 0,20 & 0,10 & $<001$ & 1,18 & 1,89 & 1,89 & 1,31 & 0,71 \\
\hline $\mathrm{mg} \#$ & 0,27 & 0,25 & 0,35 & 0,33 & 0,33 & 0,43 & 0,41 & 0,37 & 0,39 & 0,45 & 0,41 & 0,27 & 0,40 & 0,40 & 0,31 \\
\hline Total & 99,76 & 98,75 & 99,95 & 99,87 & 99,96 & 99,93 & 99,95 & 99,95 & 99,94 & 100,03 & 99,65 & 100,40 & 99,69 & 99,02 & 99,35 \\
\hline$\overline{\mathrm{Cr}}$ & 87,00 & 37,00 & 25,00 & 29,00 & 27,00 & 41,00 & 43,00 & 18,00 & 41,00 & 86,00 & 144,00 & 86,00 & 160,00 & 149,00 & 130,00 \\
\hline $\mathrm{Ni}$ & 56,10 & 25,80 & 16,60 & 34,70 & 18,60 & 42,80 & 42,10 & 34,10 & 51,00 & 124,00 & 96,00 & 58,00 & 95,00 & 93,00 & 42,00 \\
\hline $\mathrm{Ba}$ & 294,90 & 331,10 & 188,10 & 268,40 & 71,70 & 134,40 & 146,00 & 150,30 & 160,40 & 125,00 & 166,00 & 414,00 & 167,00 & 166,00 & 186,00 \\
\hline $\mathrm{Nb}$ & 10,80 & 12,90 & 13,00 & 24,50 & 6,80 & 8,20 & 9,60 & 9,10 & 10,10 & 11,00 & 11,00 & 16,00 & 11,00 & 11,00 & 18,00 \\
\hline $\mathrm{Rb}$ & 14,70 & 18,70 & 10,80 & 13,60 & 5,50 & 5,70 & 6,90 & 7,90 & 7,20 & 13,00 & 14,00 & 31,00 & 12,00 & 14,00 & 5,00 \\
\hline $\mathrm{Sr}$ & 213,70 & 216,10 & 421,80 & 602,00 & 238,80 & 257,90 & 280,40 & 296,20 & 261,80 & 231,00 & 219,00 & 197,00 & 229,00 & 225,00 & 219,00 \\
\hline $\mathrm{Zr}$ & 167,60 & 218,10 & 99,90 & 173,40 & 97,80 & 93,80 & 111,90 & 99,60 & 111,20 & 62,00 & 100,00 & 169,00 & 105,00 & 108,00 & 186,00 \\
\hline Y & 41,70 & 50,50 & 20,50 & 24,10 & 25,20 & 21,10 & 25,20 & 22,90 & 24,60 & 15,40 & 2,79 & 12,30 & 2,92 & 2,96 & 5,13 \\
\hline Th & 2,50 & 2,60 & 2,00 & 2,70 & 0,60 & 0,90 & 1,20 & 0,70 & 0,70 & $\mathrm{ND}$ & $\mathrm{ND}$ & $\mathrm{ND}$ & $\mathrm{ND}$ & ND & $\mathrm{ND}$ \\
\hline$\overline{\mathrm{La}}$ & 17,80 & 20,60 & 18,40 & 26,40 & 8,40 & 12,30 & 13,80 & 12,60 & 12,90 & 7,56 & ND & ND & ND & ND & ND \\
\hline $\mathrm{Ce}$ & 37,80 & 45,20 & 36,70 & 58,20 & 19,70 & 23,90 & 29,60 & 26,90 & 29,60 & 15,10 & ND & ND & ND & ND & ND \\
\hline $\operatorname{Pr}$ & 5,29 & 6,26 & 5,03 & 7,71 & 3,03 & 3,32 & 4,01 & 3,55 & 3,96 & $\mathrm{ND}$ & ND & ND & ND & ND & $\mathrm{ND}$ \\
\hline $\mathrm{Nd}$ & 24,90 & 29,60 & 20,20 & 32,70 & 15,60 & 15,20 & 19,90 & 16,60 & 18,90 & 9,00 & ND & ND & ND & ND & ND \\
\hline $\mathrm{Sm}$ & 6,50 & 7,20 & 4,60 & 7,30 & 4,30 & 3,30 & 5,00 & 4,30 & 3,90 & 2,23 & ND & ND & ND & ND & ND \\
\hline $\mathrm{Eu}$ & 2,16 & 2,44 & 1,43 & 2,35 & 1,56 & 1,50 & 1,73 & 1,46 & 1,51 & 1,13 & ND & ND & ND & ND & ND \\
\hline $\mathrm{Gd}$ & 8,24 & 9,71 & 4,62 & 6,37 & 4,65 & 4,25 & 4,67 & 4,58 & 4,73 & 2,95 & ND & ND & ND & ND & ND \\
\hline $\mathrm{Tb}$ & 1,30 & 1,59 & 0,58 & 0,87 & 0,86 & 0,55 & 0,83 & 0,63 & 0,60 & ND & ND & ND & ND & ND & ND \\
\hline Dy & 7,31 & 9,50 & 3,98 & 4,93 & 4,98 & 4,31 & 4,83 & 4,40 & 4,89 & 3,49 & ND & ND & ND & ND & ND \\
\hline $\mathrm{Ho}$ & 1,61 & 2,01 & 0,74 & 0,94 & 0,91 & 0,82 & 0,99 & 0,93 & 0,88 & ND & ND & ND & ND & ND & ND \\
\hline Er & 4,50 & 5,12 & 1,97 & 2,15 & 2,48 & 2,43 & 2,77 & 2,22 & 2,58 & 1,94 & ND & ND & $\mathrm{ND}$ & ND & $\mathrm{ND}$ \\
\hline $\mathrm{Tm}$ & 0,61 & 0,68 & 0,30 & 0,33 & 0,33 & 0,29 & 0,36 & 0,29 & 0,41 & ND & $\mathrm{ND}$ & ND & $\mathrm{ND}$ & ND & ND \\
\hline $\mathrm{Yb}$ & 3,74 & 4,48 & 1,56 & 1,84 & 2,18 & 2,17 & 2,62 & 2,12 & 1,87 & 1,72 & ND & ND & ND & ND & ND \\
\hline $\mathrm{Lu}$ & 0,69 & 0,75 & 0,35 & 0,29 & 0,40 & 0,31 & 0,38 & 0,31 & 0,40 & 0,24 & ND & ND & $\mathrm{ND}$ & ND & ND \\
\hline$\overline{(L a / Y b) n}$ & 3,24 & 3,13 & 4,89 & 3,61 & 2,62 & 3,85 & 3,58 & 4,04 & 4,69 & 2,99 & ND & ND & ND & ND & ND \\
\hline$(\mathrm{L} a / \mathrm{Sm}) \mathrm{n}$ & 1,71 & 1,79 & 2,05 & 1,75 & 1,22 & 2,33 & 1,72 & 1,83 & 2,07 & 2,12 & ND & ND & ND & $\mathrm{ND}$ & ND \\
\hline$(\mathrm{Sm} / \mathrm{Yb}) \mathrm{n}$ & 1,89 & 1,74 & 2,37 & 2,07 & 2,14 & 1,65 & 2,07 & 2,20 & 2,27 & 1,41 & ND & $\mathrm{ND}$ & $\mathrm{ND}$ & $\mathrm{ND}$ & ND \\
\hline
\end{tabular}


$\mathrm{MgO}$. $\mathrm{Zr}, \mathrm{Y}, \mathrm{Rb}$, Ba e Nb comportam-se de forma semelhante, apresentando aumento de seus teores com a evolução magmática, enfatizando o caráter incompatível desses elementos no magma. Em relação ao Sr, a maioria das amostras apresenta valores aproximadamente constantes (entre 200 e 300 ppm), a exceção de duas amostras (com valores de 401 e 608 ppm).

Na Figura 10A, é apresentado o diagrama multielementar de elementos incompatíveis, normalizados para o
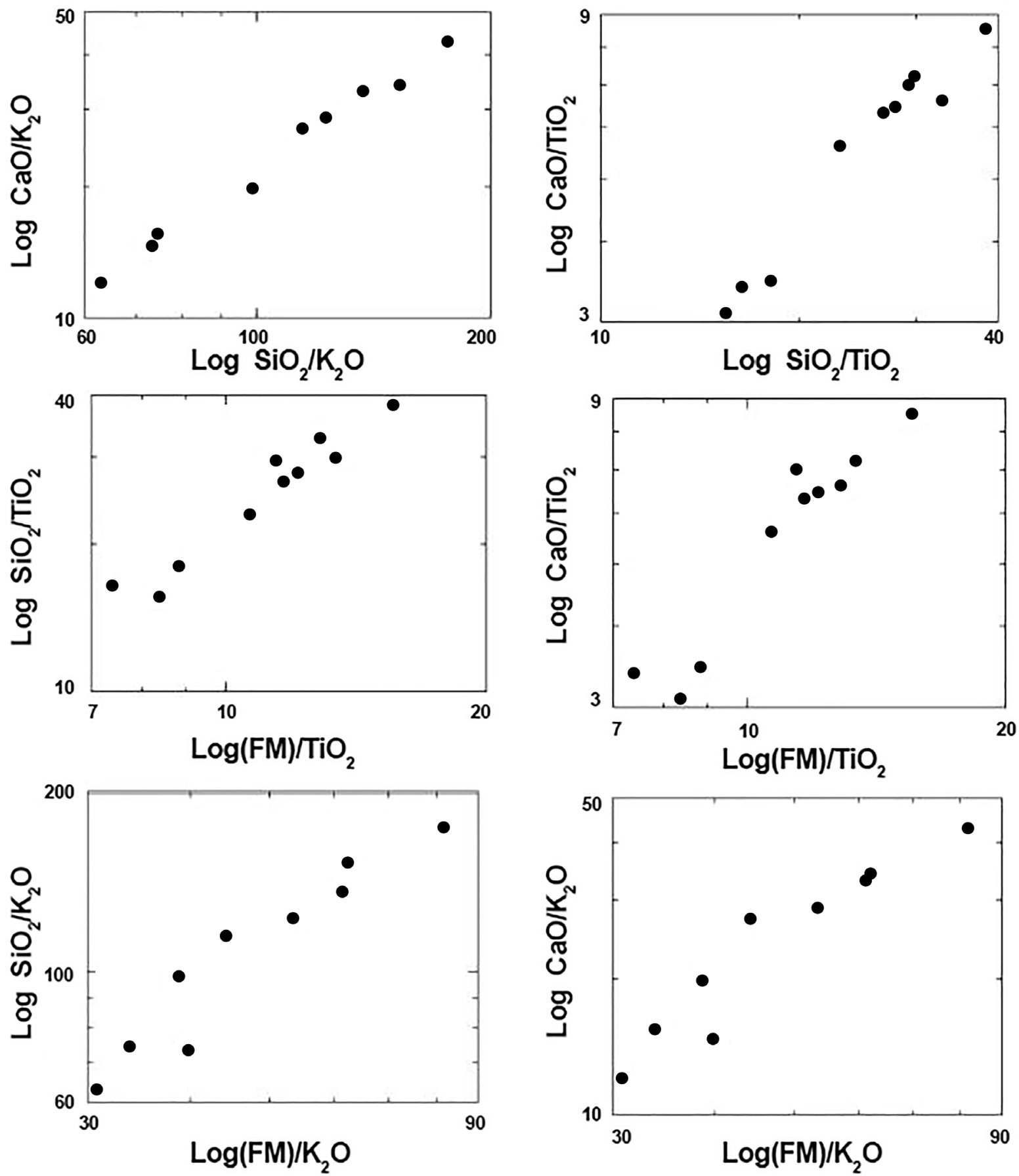

FM: somatório das proporções moleculares de $\mathrm{Fe}_{2} \mathrm{O}_{3}, \mathrm{MgO}$ e $\mathrm{MnO}$.

Figura 5. Diagramas das razões de proporções moleculares dos diques máficos estudados. 
manto primitivo (McDonough e Sun, 1995). Esse diagrama constitui uma importante ferramenta na indicação de fontes mantélicas, assim como comparações entre concentrações e razões de elementos incompatíveis, bem como de ambientes geotectônicos. Os padrões dos elementos incompatíveis dos diques máficos de Brumado apresentam, de maneira geral, anomalias negativas de $\mathrm{Nb}$ e positivas de $\mathrm{Sr}, \mathrm{Ba}, \mathrm{Ce}$ e La. Essa distribuição geoquímica é consistente com intrusões máficas em ambientes intracratônicos ou de arcos continentais (Hergt et al., 1991; Arndt e Christensen, 1992; Mazzucchelli et al., 1995; Rivalenti et al., 1995, 2007; Wang et al., 2016;

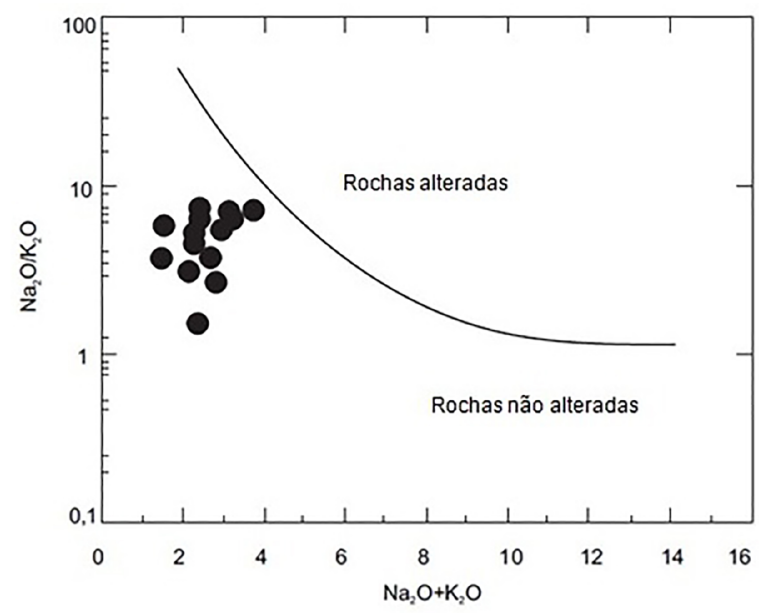

Figura 6. Diagrama de Miyashiro (1975) para discriminação de rochas que sofreram alterações por processos hidrotermais aplicado para os diques máficos estudados.
Zanetti et al., 2016). Um dos modelos utilizados para a origem de magmas com tais características é atribuído à subducção da crosta oceânica coberta de sedimentos, de espessura variável, sob o manto litosférico em arcos de ilhas e continentes. Fluidos ricos em elementos litófilos de alto raio iônico (LILE) (Ba, K, Rb) e em elementos terras raras leves (ETRL) ( $\mathrm{La}, \mathrm{Ce}$ ) provenientes de sedimentos enriquecem o manto, enquanto retenção de $\mathrm{Nb}$ e Ta pela presença do rutilo e determinados anfibólios em eclogitos da placa oceânica o empobrecem nesses elementos (Ayers, 1998; Rivalenti et al., 1998; Leitch e Davies, 2001). Outra hipótese considerada na literatura considera a possibilidade de enriquecimento do manto por meio de contaminação de rochas provenientes da crosta continental. A Figura 10A compara os padrões dos diques de Brumado com os Enriched Mid-Ocean Ridge Basalt (E-MORB) e Normal Mid-Ocean Ridge Basalt (N-MORB), Ocean Island Basalt (OIB) (Sun e McDonough, 1989) e Global Subducting Sediment (GLOSS) (Plank e Langmur, 1998). Embora exista alguma semelhança com o padrão de GLOSS, nota-se que as concentrações de elementos LILE ( $\mathrm{Rb}, \mathrm{Ba}$ e K) são bem mais elevadas neste, evidência confirmada no confronto das razões que envolvem esses elementos, assim como nos elementos LREE ( $\mathrm{La}, \mathrm{Ce}$ ) (Tabela 2). De outro lado, a comparação das razões de incompatíveis entre os diques de Brumado e os valores médios da crosta inferior mostra grande semelhança no que diz respeito à maioria das razões de elementos incompatíveis $(\mathrm{Rb} / \mathrm{Sr}, \mathrm{Zr} / \mathrm{Y}$, $\mathrm{Ce} / \mathrm{Y}, \mathrm{La} / \mathrm{Y}, \mathrm{La} / \mathrm{Nb}, \mathrm{Zr} / \mathrm{Nb}$ e La/Sm) (Tabela 2).

Os padrões geoquímicos dos elementos terras raras (ETR) normalizados para o condrito, segundo McDonough e Sun (1995),
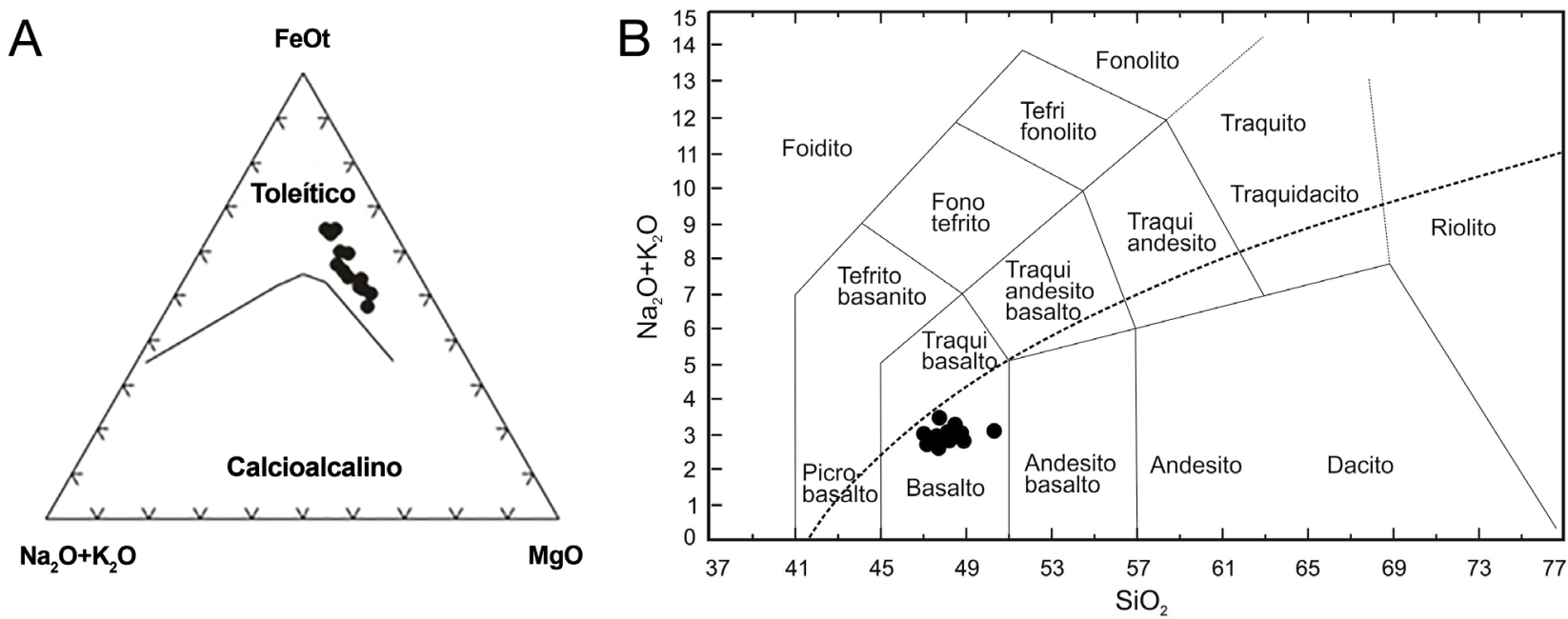

Figura 7. (A) Diagrama $A\left(\mathrm{Na}_{2} \mathrm{O}+\mathrm{K}_{2} \mathrm{O}\right), \mathrm{F}(\mathrm{FeOt}), \mathrm{M}(\mathrm{MgO})$, segundo Irvine e Baragar (1971), para os diques máficos estudados. A linha cheia representa a suíte toleítica do Hawaii, segundo MacDonald e Katsura (1964); (B) diagrama total de álcalis versus sílica (TAS), segundo Le Bas et al. (1986), para os diques máficos de Brumado. A linha tracejada divide o campo dos basaltos, de acordo com Zanettin (1984). 

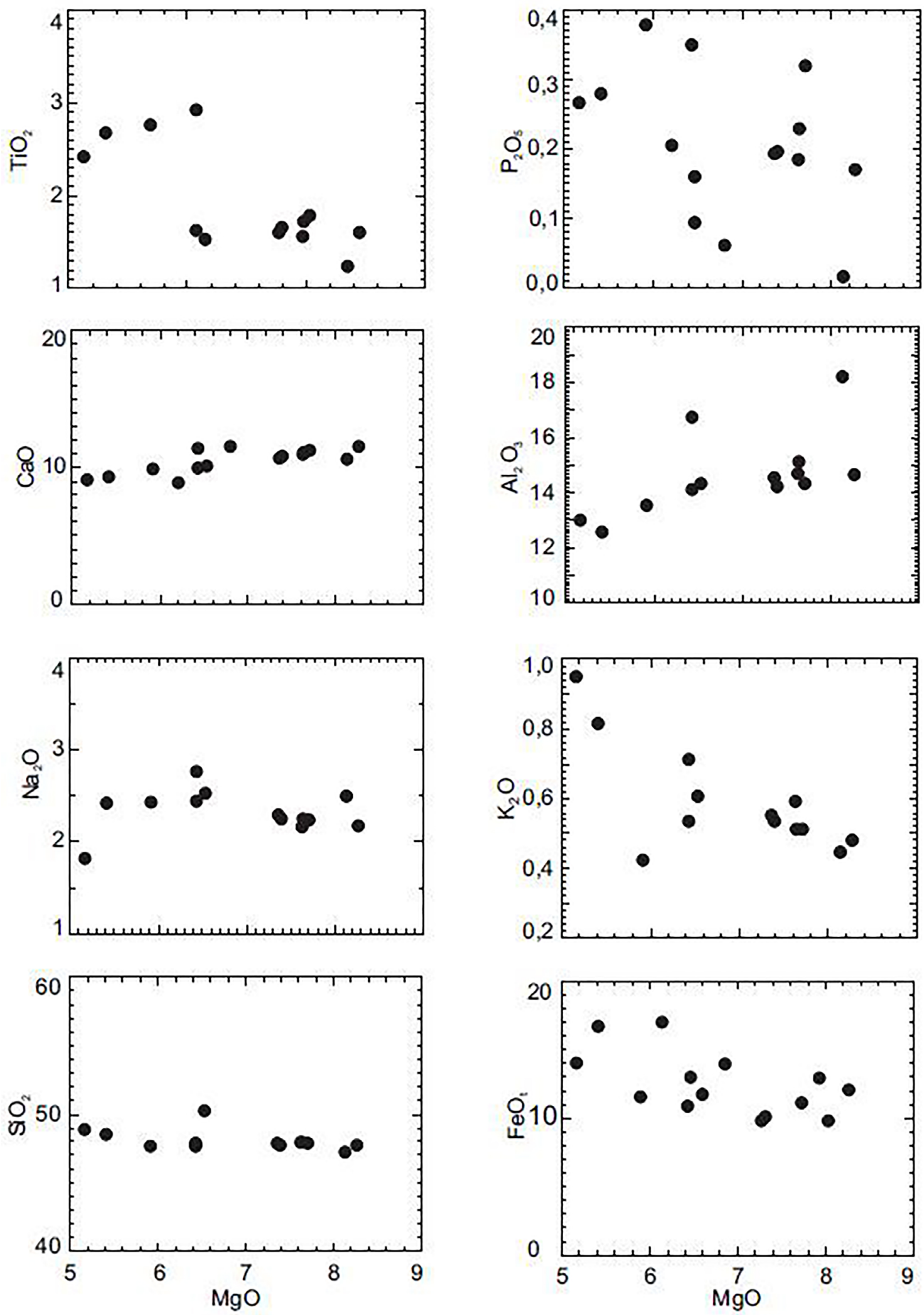

Figura 8. Diagramas de variação química do $\mathrm{MgO}$ (\% em peso) versus elementos maiores (\% em peso) para os diques máficos estudados. 

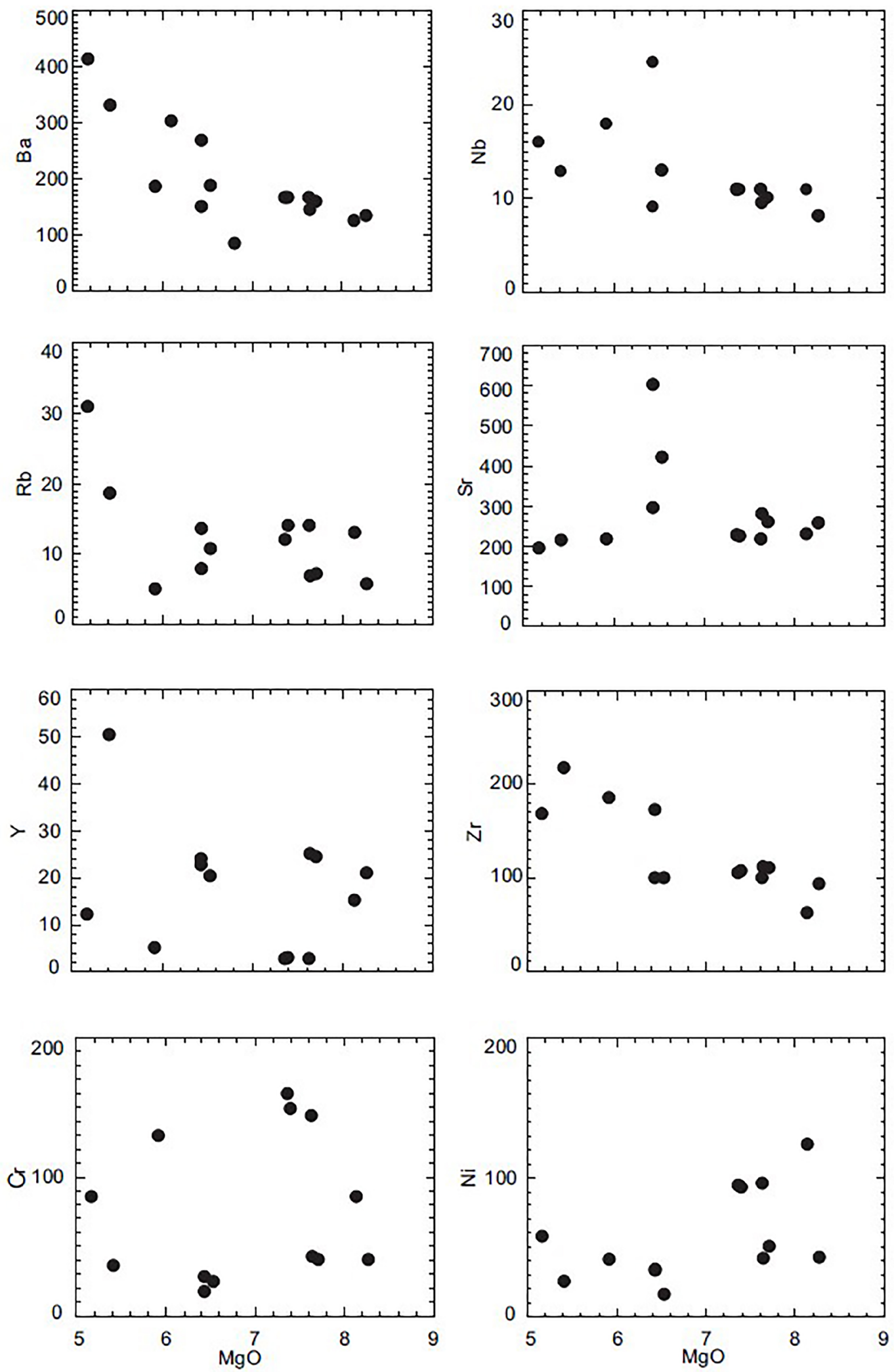

Figura 9. Diagrama de variação química do $\mathrm{MgO}$ (\% em peso) versus elementos traço (em ppm) para os diques máficos estudados. 
mostram que os diques máficos apresentam disposição espacial sub-horizontal a discretamente fracionado em elementos terras raras pesados (ETRP), com anomalias levemente negativas de Eu. Apresentam discreto fracionamento com valores de $(\mathrm{La} / \mathrm{Sm})_{\mathrm{N}}$ variando de 1,22 a 2,33 (média $=1,86 \pm 0,29),(\mathrm{La} / \mathrm{Yb})_{\mathrm{N}}$ variando de 2,62 a 4,89 (média $=3,66 \pm 0,69)$ e $(\mathrm{Sm} / \mathrm{Yb})_{\mathrm{N}}$ entre 1,41 e 2,37 (média $=1,98 \pm 0,29$ ) (Figura 10B). O padrão apresentado é característico de suítes toleíticas. Comparando o padrão dos ETR dos diques máficos estudados com o do Mid-Ocean Ridge Basalt (MORB) (Sun e McDonough, 1989) tipos E-MORB, N-MORB, do OIB e do GLOSS (Plank e Langmur, 1998), observa-se que os diques estudados possuem valores semelhantes aos padrões E-MORB, e valores levemente enriquecidos em
ETRL (diques estudados $=1,86 \pm 0,29 ; \mathrm{MP}=1,60$ ) e ETRP (diques estudados $=1,98 \pm 0,29 ; \mathrm{MP}=0,98$ ) em relação ao Manto Primitivo (MP) (Figura 10B). No diagrama $\mathrm{Th} / \mathrm{Yb}$ versus $\mathrm{Nb} / \mathrm{Yb}$ (Figura 11), as amostras estudadas situam-se dentro do alinhamento MORB-OIB, próximas do E-MORB, exceto uma amostra que se aproxima do OIB.

\section{NATUREZA DA FONTE MAGMÁTICA E CONSIDERAÇÕES FINAIS}

Para avaliar a origem da fonte dos litotipos, as razões $\mathrm{Zr}$ versus elementos incompatíveis (EI) são excelentes indicadores
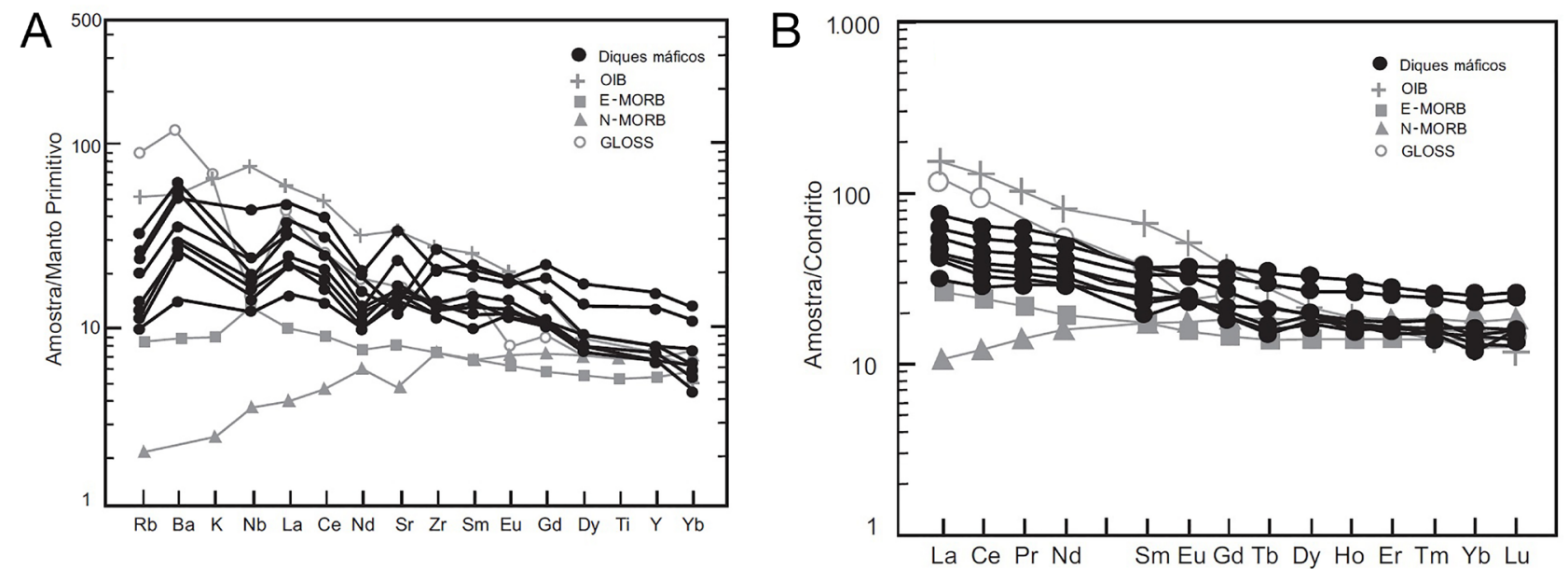

Figura 10. (A) Diagrama multielementar para os diques máficos estudados e (B) padrão de distribuição dos elementos terras raras para os diques máficos estudados. Padrões dos ambientes Ocean Island Basalt, Enriched Mid-Ocean Ridge Basalt e Normal Mid-Ocean Ridge Basalt, de acordo com Sun e McDonough (1989), e Global Subducting Sediment (Plank e Langmur, 1998), para comparação.

Tabela 2. Valores médios de razões de elementos incompatíveis dos diques máficos estudados, do Global Subducting Sediment (Plank e Langmuir, 1998), do Normal-Mid-Ocean Ridge Basalt, do Enriched-Mid-Ocean Ridge Basalt (McDonough e Sun, 1995), do Ocean Island Basalt (Sun e McDonough, 1989) e Crosta Inferior (Hacker et al., 2015), Crosta Superior (Taylor e McLennan, 1985), Crosta continental (CC) média (Weaver, 1991).

\begin{tabular}{|c|c|c|c|c|c|c|c|c|}
\hline & $\begin{array}{l}\text { Diques de } \\
\text { Brumado }\end{array}$ & GLOSS & N-MORB & E-MORB & OIB & $\begin{array}{l}\text { Crosta } \\
\text { Inferior }\end{array}$ & $\begin{array}{l}\text { Crosta } \\
\text { Superior }\end{array}$ & $\begin{array}{c}\text { Crosta } \\
\text { Continental } \\
\text { (média) }\end{array}$ \\
\hline $\mathrm{Rb} / \mathrm{Sr}$ & 0,04 & 0,17 & 0,01 & 0,03 & 0,05 & 0,03 & 0,32 & 0,24 \\
\hline $\mathrm{Zr} / \mathrm{Y}$ & 4,61 & 4,36 & 2,64 & 3,32 & 9,66 & 4,25 & 8,63 & 5,00 \\
\hline $\mathrm{Ce} / \mathrm{Y}$ & 1,24 & 1,92 & 0,26 & 0,68 & 2,75 & 1,25 & 2,90 & 1,81 \\
\hline $\mathrm{Ba} / \mathrm{Nb}$ & 16,43 & 86,80 & 2,70 & 7,12 & 7,29 & 51,80 & 22,00 & 54,00 \\
\hline $\mathrm{La} / \mathrm{Yb}$ & 6,75 & 10,40 & 0,82 & 2,66 & 17,12 & 5,30 & 13,63 & 8,82 \\
\hline $\mathrm{Ti} / \mathrm{Zr}$ & 101,04 & 28,60 & 103,00 & 82,00 & 61,00 & 72,30 & 0,82 & 26,66 \\
\hline $\mathrm{La} / \mathrm{Nb}$ & 1,30 & 3,20 & 1,07 & 0,76 & 0,77 & 1,60 & 1,20 & 2,20 \\
\hline $\mathrm{Ti} / \mathrm{Y}$ & 433,57 & 124,70 & 271,00 & 273,00 & 593,00 & 307,20 & 7,10 & 133,33 \\
\hline $\mathrm{Ba} / \mathrm{La}$ & 12,40 & 26,90 & 2,52 & 9,04 & 9,46 & 32,40 & 18,33 & 25,00 \\
\hline $\mathrm{Zr} / \mathrm{Nb}$ & 11,23 & 14,50 & 31,76 & 8,79 & 5,80 & 13,60 & 7,60 & 16,20 \\
\hline $\mathrm{La} / \mathrm{Sm}$ & 3,13 & 5,00 & 0,95 & 2,42 & 3,70 & 3,07 & 6,66 & 5,00 \\
\hline
\end{tabular}

GLOSS: Global Subducting Sediment; N-MORB: Normal Mid-Ocean Ridge Basalt; E-MORB: Enriched Mid-Ocean Ridge Basalt; OIB: Ocean Island Basalt. 


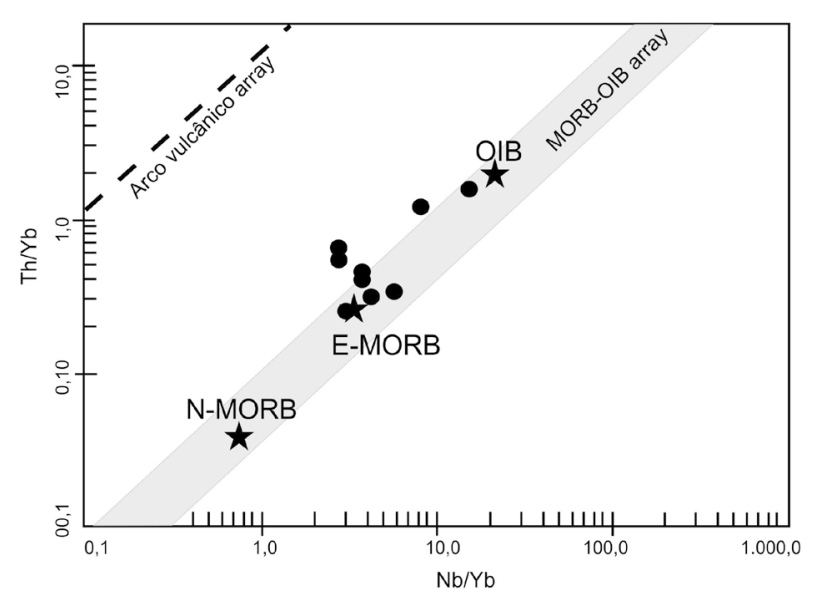

N-MORB: Normal Mid-Ocean Ridge Basalt; E-MORB: Enriched Mid-Ocean Ridge Basalt; OlB: Ocean Island Basalt.

Figura 11. Diagrama $\mathrm{Th} / \mathrm{Yb}$ versus $\mathrm{Nb} / \mathrm{Yb}$ (Pearce, 2008) para os diques máficos estudados.
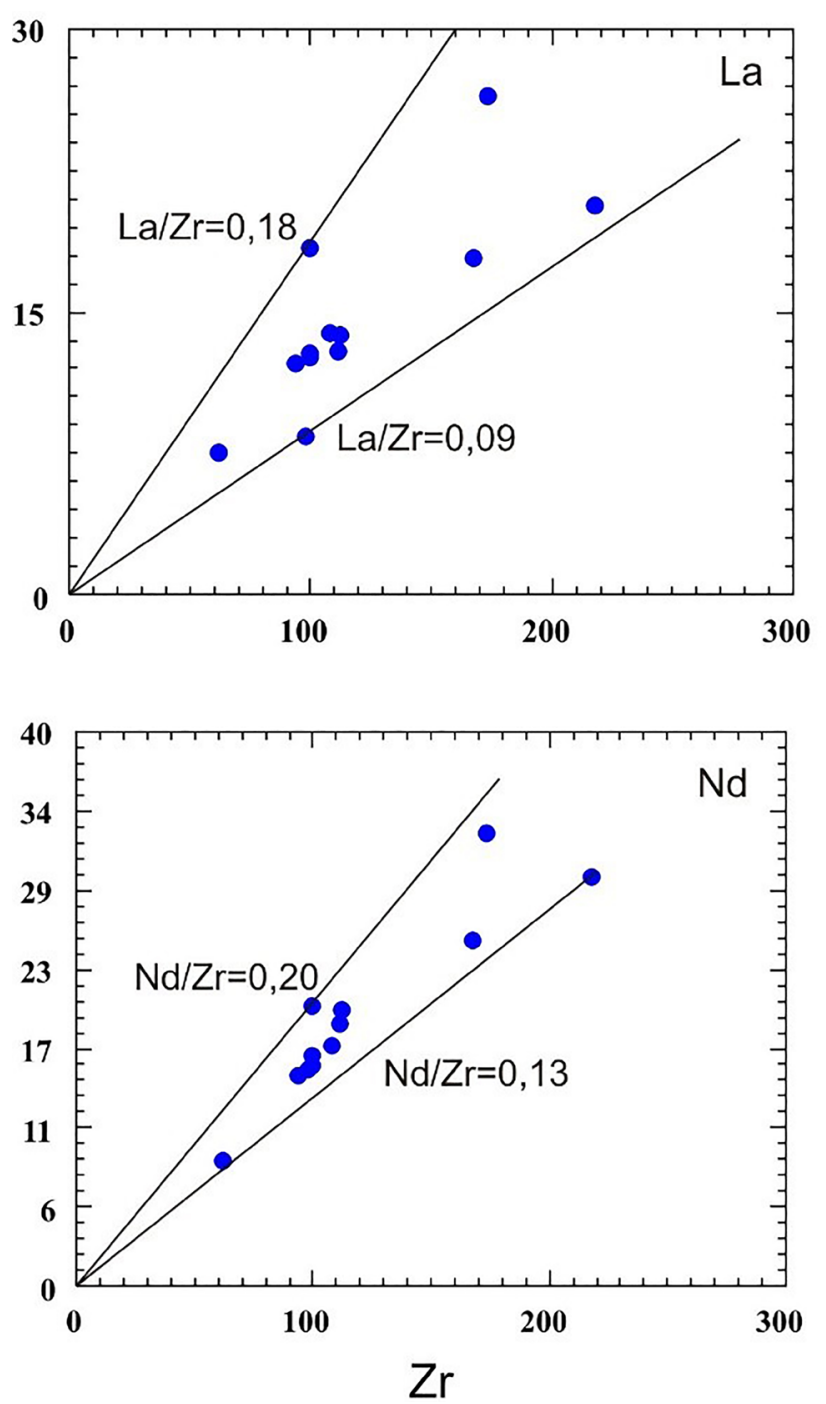

petrogenéticos, destacando-se como uma boa ferramenta para o estudo das propriedades e dos processos de gênese das rochas e da investigação de heterogeneidade mantélica, em consequência do pouco fracionamento desses elementos durante o processo de cristalização fracionada ou fusão parcial. Na Figura 12, observa-se uma correlação positiva entre $\mathrm{Zr}$ e La, Y, Nd e Ce, mostrando pequenas variações em suas razões, sugerindo uma fonte mantélica pouco heterogênea para os diques máficos.

A análise global dos dados geoquímicos indicou que processos secundários não interferiram na evolução ígnea da suíte toleítica, e sugerem fonte original do tipo E-MORB. A Figura 11 mostra que as amostras dos diques estudados se situam dentro do campo definido pelo alinhamento N-MORB - OIB, sendo a maioria delas situada junto ao polo E-MORB, e apenas uma junto ao polo OIB, o que sugere restrita e talvez local influência desse componente
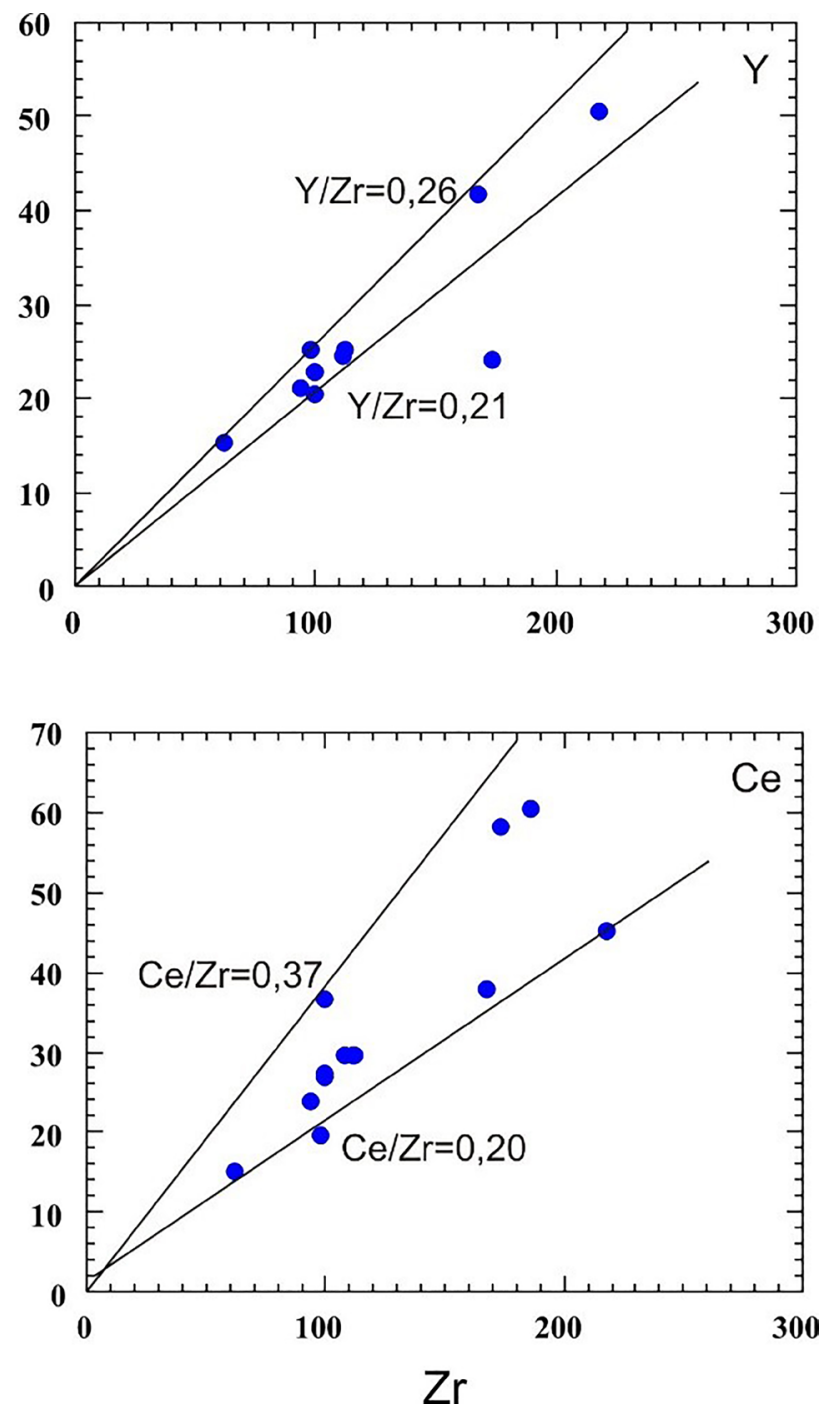

Figura 12. Diagramas de correlação entre $\mathrm{Zr}(\mathrm{ppm})$ e elementos traço (ppm) para os diques máficos estudados. 
na origem do manto parental. As três amostras restantes situam-se paralelamente junto ao contorno externo do alinhamento, não mostrando tendência no aumento das razões $\mathrm{Th} / \mathrm{Yb}$, e consequente deslocamento vertical, feição típica da influência de sedimentos subductados (Pearce, 2008). Diagramas multielementares e razões de elementos incompatíveis são coerentes com esse quadro, sendo que as razões sugerem que o enriquecimento do MP se deveu à contaminação da crosta continental inferior (Tabela 2). Estudos mencionados anteriormente sugerem a possibilidade de serem os enxames de Brumado e os da Chapada Diamantina relacionados cronologicamente. Se tal ocorre, os dados geoquímicos disponíveis indicam que as fontes mantélicas podem ser diferentes, em razão das diferenças entre as razões de elementos incompatíveis e a possibilidade de o manto parental do enxame da Chapada Diamantina ser mais heterogêneo que o de Brumado, dada a avaliação na variação dos componentes MORB e OIB nos diques da Chapada Diamantina (Girardi et al., 2017). A elaboração de dados isotópicos em Brumado será muito importante para a elucidação dessa discussão.

\section{AGRADECIMENTOS}

Agradecemos a Coordenação de Aperfeiçoamento de Pessoal de Nível Superior (CAPES), o apoio por meio da concessão de bolsa da primeira autora; e o Conselho Nacional de Desenvolvimento Científico e Tecnológico (CNPq), o apoio financeiro (Processo CNPq 47690187/2013-8). Os autores também agradecem aos revisores da Revista Geologia USP. Série Científica as valiosas contribuições ao trabalho.

\section{REFERÊNCIAS}

Arcanjo, J. B. A., Martins, A. A. M., Loureiro, H. S. C., Varela, P. H. L. (2000). Projeto vale do Paramirim, escala 1:100.000. Salvador: CPRM, Programa de Levantamentos Geológicos Básicos do Brasil. 105p.

Arndt, N. T., Christensen, U. (1992). The role of lithospheric mantle in continental flood volcanism: thermal and geochemical constraints. Journal of Geophysical Research, 97(B7), 10967-10981. https:// doi.org/10.1029/92JB00564

Ayers, J. (1998). Trace element modeling of aqueous fluidperidotite interaction in the mantle wedge of subduction zones. Contribution Mineralogy and Petrology, 132(4), 390-404. https://doi.org/10.1007/s004100050431
Barbosa, J. S. F., Dominguez, J. M. L. (1996). Texto Explicativo para o Mapa Geológico da Bahia ao Milionésimo. Salvador, SICM/SGM. 400p.

Barbosa, J. S. F., Sabaté, P. (2004). Archean and paleoproterozoic crust of the São Francisco Craton, Bahia, Brazil: geodynamic features. Precambrian Research, 133(1-2), 1-27. https://doi. org/10.1016/j.precamres.2004.03.001

Barbosa, J. S. F., Santos-Pinto, M. A., Cruz, S. S. P., Souza, J. S. (2012). Granitoides. In: J. S. F. Barbosa (Ed.). Geologia da Bahia. Pesquisa e Atualização (1, 327-296). Salvador.

Bastos Leal, L. R. (1998). Geocronologia U/Pb (Shrimp), $207 \mathrm{~Pb} / 206 \mathrm{~Pb}, \mathrm{Rb} / \mathrm{Sr}, \mathrm{Sm} / \mathrm{Nd}$ e $\mathrm{K} / \mathrm{Ar}$ dos terrenos granitogreenstone do Bloco Gavião: Implicações para a evolução arqueana e paleoproterozóica do Cráton do São Francisco, Brasil. Tese (Doutorado). São Paulo: Instituto de Geociências, Universidade de São Paulo, 176p. https:// doi.org/10.11606/T.44.2016.tde-08012016-145912

Bastos Leal, L. R., Cunha, J. C., Cordani, U. G., Teixeira, W., Nutman, A. P., Menezes Leal,A. B., Macambira, M. J. B. (2003). SHRIMP U-Pb, 207Pb/206 Pb zircon dating and $\mathrm{Nd}$ isotopic signature of the Umburanas greenstone belt, Northern São Francisco Craton, Brazil. Journal of South American Earth Sciences, 15(7), 775-785. https://doi.org/10.1016/S0895-9811(02)00129-3

Bastos Leal, L. R., Cunha, J. C., Teixeira, W., Macambira, M. J. B. (1998). Archaean tonalitic-trondhjemitic and granitic plutonism in the Gavião Block, São Francisco Craton, Bahia, Brazil: geochemical and geochronological characteristics. Revista Brasileira de Geociências, 28(2), 209-220.

Beswick, A. E. (1982). Some geochemical aspects of alteration and genetic relations, in Komatiitic suites. In: $\mathrm{N}$. T. Arndt, E. G. Nesbit (Eds.). Komatiites. Londres: George, Allen and Unwin, p. 283-308.

Beswick, A. E., Soucie, G. (1978). A correction procedure for metassomatism in an Archaean greenstone belt. Precambrian Research, 6(2), 235-248. https://doi. org/10.1016/0301-9268(78)90015-3

Brito, D. C. (2005). Caracterização petrográfica das rochas basálticas da Chapada Diamantina - Bahia. Monografia (Graduação). Salvador: Instituto de Geociências, Universidade Federal da Bahia, 80p.

Brito, D. C. (2008). Geologia, petrografia e litogeoquímica dos diques máficos que ocorrem na porção sudoeste da Chapada Diamantina, Bahia, Brasil. Dissertação (Mestrado). Salvador: Instituto de Geociências, Universidade Federal da Bahia, 107p. 
Corrêa da Costa, P. C. (2003). Petrologia, Geoquímica e Geocronologia dos Diques Máficos da Região de Crixás-Goiás, Porção Centro-Oeste do Estado de Goiás. Tese (Doutorado). São Paulo: Inst. de Geociências, Universidade de São Paulo, 151p.

Corrêa da Costa, P. C., Carneiro, M. A., Teixeira, W., Girardi, V. A. V., Nalini Júnior, H. A., Oliveira, A. H., Fernandes, R. A. (2006). Estudo geoquímico e petrológico dos diques máficos da Região de Candeias-Campo Belo-Santo Antônio do Amparo (MG), porção meridional do Craton São Francisco. Geologia USP. Série Cientifica, 5(2), 65-84. https://doi. org/10.5327/S1519-874X2006000100005

Corrêa da Costa, P. C., Girardi, V.A. V., Matos, J. B., Ruiz, A. S. (2009). Geocronologia Rb-Sr e Características Geoquímicas dos Diques Máficos da Região de Nova Lacerda e Conquista D Oeste (MT), Porção Sudoeste do Craton Amazônico. Geologia USP. Série Cientifica, 9(1), 115-132. https://doi. org/10.5327/Z1519-874X2009000100008

Corrêa-Gomes, L. C., Tanner de Oliveira, M. A. F., Mota, A. C., Cruz, M. J. M. (1996). Província de Diques Máficos do Estado da Bahia. Mapa, estágio atual do conhecimento e evolução temporal. Salvador: Superintendência de Geologia e Recursos Minerais - SGM/SICM. 144p.

CPRM/CBPM. (2003). Geologia e recursos minerais do estado da Bahia - Sistema de Informações Geográficas SIG, escala 1:1.000.000. Brasil, CPRM/CBPM.

Cruz Filho, B. E., Rios, D. C., Scheller, T., Conceição, H., Macambira, M. J. B., Oliveira, A. E. L., Burgos, C. M. G. (1999). Petrography and $\mathrm{Pb}-\mathrm{Pb}$ age of the Nordestina batholith, northeastern of the State of Bahia. In: II South American Symposium on Isotopic Geology. Córdoba.

Cunha, J. C., Fróes, R. J. B. (1994). Komatiitos com textura spinifex do Greenstone Belt de Umburanas, Bahia. Salvador, CBPM, 29p.

Giovanardi, T., Girardi, V. A. V., Teixeira, W., Mazzucchelli, M. (2019). Mafic dyke swarms at 1882, 535 and $200 \mathrm{Ma}$ in the Carajás region, Amazonian Craton: Sr-Nd isotopy, trace element geochemistry and inferences on their origin and geological settings. Journal of South American Earth Sciences, 92, 197-208. https://doi.org/10.1016/j.jsames.2019.02.017

Girardi, V. A. V., Corrêa da Costa, P. C., Teixeira, W. (2011). Petrology and $\mathrm{Sr}-\mathrm{Nd}$ characteristics of the Nova Lacerda dike swarm, SW Amazonian Craton: new insights regarding its subcontinental mantle source and Mesoproterozoic geodynamics. International Geology Review, 54(2), 165182. https://doi.org/10.1080/00206814.2010.510238
Girardi, V. A. V., Teixeira, W., Mazzucchelli, M., Corrêa da Costa, P. C. (2013). Sr-Nd constraints and trace-elements geochemistry of selected Paleo and Mesoproterozoic mafic dikes and related intrusions from the South American Platform: Insights into their mantle sources and geodynamic implications. Journal of South American Earth Science, 41, 65-82. https://doi.org/10.1016/j.jsames.2012.09.006

Girardi, V.A. V., Teixeira, W., Mazzucchelli, M., Oliveira, E. P., Corrêa da Costa, P. C. (2017). Mafic dykes: petrogenesis and tectonic inferences. In: M. Helibron, U. G. Cordani, F. Alkmim. (Eds.). Regional Geology Reviews, v. 1, p. 145-169. Suíça: Springer.

Guimarães, J. T., Martins, A. A. M., Andrade Filho, E. L., Loureiro, H. S. C., Arcanjo J. B. A., Neves, J. P., Abram, M. B., Silva, M. G., Melo, R. C., Teixeira, L., Bento, R. V. (2005). Projeto Ibitiara - Rio de Contas: Estado da Bahia. Escala 1:200.000. Programa Recursos Minerais do Brasil. Salvador, CPRM, $157 \mathrm{p}$.

Hacker, B. R., Kelemen, P. B., Behn, M. D. (2015). Continental lower crust. Annual Review of Earth Planet Science, 43, 167 205. https://doi.org/10.1146/annurev-earth-050212-124117

Halls, H. C. (1982). The importance and potential of mafic dyke swarms in studies of geodynamic process. Geosciences Canada, 9(3), 145-154.

Halls, H. C., Fahrig, W. F. (1987). Mafic Dyke Swarms. Geological Association of Canada, Special Paper, v. 34, 503p.

Hergt, J. M., Peate, D. W., Hawkesworth, C. J. (1991). The petrogenesis of Mesozoic Gondwana low-Ti flood basalts. Earth and Planetary Science Letters, 105(1-3), 134-148. https://doi.org/10.1016/0012-821X(91)90126-3

Irvine, T. N., Baragar, W. R. A. (1971). A guide to the chemical classification of common rocks. Canadian Journal Earth Science, 8(5), 523-548. https://doi.org/10.1139/e71-055

Jacques, A. L., Green, D. H. (1979). Determination of liquid compositions in high-pressure melting of peridotite. American Mineralogist, 64(11-12), 1312-1321.

Le Bas, M. J., Le Maitre, R. W., Streckeinsen, A., Zanettin, B. (1986). A chemical classification of volcanic rocks based on total álcali-silica diagram. Journal of Petrology, 27(3), 745-750. https://doi.org/10.1093/petrology/27.3.745

Leitch, A. M., Davies, G. F. (2001). Mantle plumes and flood basalts: enhanced melting from plume ascent and an eclogite component. Journal of Geophysical Research, 106(B2), 2047-2059. https://doi.org/10.1029/2000JB900307 
MacDonald, G. A., Katsura, T. (1964). Chemical composition of Hawaiian Lavas. Journal of Petrology, 5(1), 82-133. https://doi.org/10.1093/petrology/5.1.82

Marinho, M. M. (1991). La séquence volcano-sedimentaire de Contendas-Mirante et la bordure occidentale du Bloc Jequié (Cráton du SãoFrancisco-Brésil): un exemple de transition Archéean-Protérozoique. Tese (Doutorado). Clermont Ferrand, França: Blaise Pascal Université, 388p.

Martin, H., Sabaté, P., Peucat, J. J., Cunha, J. C. (1991). Un segment de croute continentale d'age Archéean ancien (3.4 milliards d'années): le Massif de Sete Voltas (BahiaBrésil). Comptes rendus de l'Académie des Sciences, 313(2), 531-538.

Mazzucchelli, M., Rivalenti, G., Piccirillo, E. M., Girardi, V.A. V., Civeta, L., Petrini, R. (1995). Petrology of the Proterozoic mafic dyke swarms of Uruguay and constraints on their mantle source composition. Precambrian Research, 74(3), 177-194. https://doi.org/10.1016/0301-9268(95)00014-V

McDonough, W. F., Sun, S. S. (1995). The composition of the Earth. Chemical Geology, 120(3-4), 223-253. https:// doi.org/10.1016/0009-2541(94)00140-4

Menezes Leal, A. B. (1992). Enxame de diques máficos de Uaua-Bahia: caracterização petrológica e geoquímica. Dissertação (Mestrado). São Paulo: Instituto de Geociências, Universidade de São Paulo, 126p. https:// doi.org/10.11606/D.44.1992.tde-28102015-101141

Menezes Leal, A. B. (1997). Contribuição a Petrologia e Geoquímica do Magmatismo Basáltico Mesozóico do Estado de Roraima. Tese (Doutorado). São Paulo: Instituto de Geociências, Universidade de São Paulo, 137p. https:// doi.org/10.11606/T.44.1997.tde-29102015-110231

Menezes Leal, A. B., Barbosa, N. S., Leal, L. R. B., Cunha, J. C. (2016). Geocronologia U-Pb em zircão do greenstone belt Umburanas, bloco Gavião, cráton do São Francisco. In: XLVIII Congresso Brasileiro de Geologia. Porto Alegre: SBG.

Menezes Leal, A. B., Bastos Leal, L. R., Cunha, J. C., Teixeira, W. (2005). Características geoquímicas dos granitóides transamazônicos no Bloco do Gavião, Cráton do São Francisco, Bahia, Brasil. Geochimica Brasiliensis, 19(1), 8-21. https://doi.org/10.21715/gb.v19i1.219

Menezes Leal, A. B., Corrêa-Gomes, L. C., Guimarães, J. T. (2012). Diques Máficos. In: J. S. F. Barbosa (Eds.). Geologia da Bahia. Pesquisa e Atualização. Salvador: CBPM, p. 199-231.
Miyashiro, A. (1975). Classification, characteristics, and origin of ophiolites. Journal of Geology, 83(2), 249-281. https://www.jstor.org/stable/30060218

Nutman, A. P., Cordani, U. G. (1993). SHRIMP U-Pb zircon geochronology of Archean granitoids from the ContendasMirante area of the São Francisco Craton, Bahia, Brazil. Precambrian Research, 63(3-4), 179-188. https://doi. org/10.1016/0301-9268(93)90032-W

Oliveira, E. P., Montes, M. L. (1984). Os enxames de diques máficos do Brasil. In: XXXIII Congresso Brasileiro Geologia, p. 4137-4154. Rio de Janeiro: SBG.

Pearce, T. H. (1968). A contribution to the theory of variation diagrams. Contribution of Mineralogy and Petrology, 19(2), 142-157. https://doi.org/10.1007/BF00635485

Pearce, J. A. (2008). Geochemical fingerprinting of oceanic basalts with applications to ophiolite classification and the search for Archean oceanic crust. Lithos, 100(1-4), 14-48. https://doi.org/10.1016/j.lithos.2007.06.016

Pereira, L. M. (2007). Geologia Petrografia e Geoquimica dos diques máficos da porção sudoeste do bloco Gavião, Bahia, Brasil. Monografia (Graduação). Salvador: Instituto de Geociências, Universidade Federal da Bahia, 80p.

Pereira Varjão, L. M. (2017). Petrologia da província de diques máficos Chapada Diamantina Paramirim. Correlação Geológica-Geofísica preliminar. In: III Oficina de avaliação e acompanhamento do Programa de PósGraduação em Geologia UFBA. Caderno de Resumos, p 30. Bahia.

Pereira Varjão, L. M., Menezes Leal, A. B. (2017). Correlação Geoquímica e Investigação da fonte mantélica dos diques máficos da Chapada Diamantina e do Bloco Gavião (Brumado) Bahia, Brasil. XVI Simpósio Nacional de Estudos Tectônicos, p. 215-218. Salvador.

Pinheiro Amorim, A. C. (2017). Petrologia dos Enxames de Diques Máficos Ectasiano de Itajú do Colônia e Criogeniano de Itapé, Sudeste do Estado da Bahia. Tese (Doutorado). Salvador: Instituto de Geociências, Universidade Federal da Bahia, 227p.

Plank, T., Langmuir C. H. (1998). The chemical composition of subducting sediment and its consequences for the crust and mantle. Chemical Geology, 145, 325-394. 
Rivalenti, G., Mazzucchelli, M., Girardi, V. A. V., Cavazzini, G., Finatti, C., Barbieri, M. A., Teixeira, W. (1998). Petrogenessis of the Paleoproterozoic basalt-andesitrhyolite dyke association in the Carajás region - Amazonian Craton. Lithos, 43(4), 235-265. https://doi.org/10.1016/ s0024-4937(98)00015-2

Rivalenti, G., Mazzucchelli, M., Molesini, M., Petrini, R., Girardi, V. A. V., Bossi, J., Campal, N. (1995). Petrology of late proterozoic mafic dikes in the Nico Perez region, Central Uruguay. Mineralogy and Petrology, 55(4), 239263. http://dx.doi.org/10.1007/bf01165120

Rivalenti, G., Mazzucchelli, M., Zanetti, A., Vannucci, R., Bollinger, C., Hémond, C., Bertotto, G. W. (2007). Xenoliths from Cerro de los Chenques (Patagonia): an example of slab-related metasomatism in the backarc lithospheric mantle. Lithos, 99(1-2), 45-67. https://doi.org/10.1016/j. lithos.2007.05.012

Santos-Pinto, M. A. S. (1996). Le recyclage de la croûte continentale archéenne: exemple du bloc du Gavião (Bahia - Brésil). Mémoires de Géosciences Rennes, 75, 193 p.

Silveira, E. M., Söderlund, U., Oliveira, E. P., Ernst, R. E., Menezes, Leal, A. B. (2013). First precise U-Pb baddeleyite ages of 1500 Ma mafic dykes from the São Francisco Craton, Brazil, and tectonic implications. Lithos, 174, 144-156. https://doi.org/10.1016/j.lithos.2012.06.004

Sun, S.-S., McDonough, W. F. (1989). Chemical and isotopic systematic of oceanic basalts: implications for mantle composition and processes. In: A. D. Saunders e M. J. Norry (Eds.). Magmatism in the Ocean Basins. Geological Society, 42(1), 313-345. https://doi.org/10.1144/GSL. SP.1989.042.01.19

Taylor, S. R., McLennan, S. M. (1985). The Continental Crust: Its Composition and Evolution. Oxford: Blackwell Scientific.
Teixeira, W., Hamilton, M. A., Girardi, V. A. V., Faleiros, F., Ernst, R. E. (2019). U-Pb baddeleyite ages of key dyke swarms in the Amazonian Craton (Carajás/Rio Maria and Rio Apa areas). Tectonic implications for events at 1880, $1110 \mathrm{Ma}, 535 \mathrm{Ma}$ and $200 \mathrm{Ma}$. Precambrian Research, 329, 138-155. https://doi.org/10.1016/j.precamres.2018.02.008

Trindade Netto, G. B., Corrêa da Costa, P. C., Girardi, V. A. V. (2016). Contribuição à geologia, petrografia e geoquímica dos diques máficos da porção centro-leste de Rondônia, sudoeste do Cráton Amazônico. Geologia USP. Série Cientifica, 16(1), 3-21. http://dx.doi.org/10.11606/ issn.2316-9095.v16ilp3-21

Wang, X. C., Wilde, S. M., Xu, B., Pang, J. P. (2016). Origin of arc-like continental basalts: implications for deep-Earth fluids cycling and tectonic discrimination. Lithos, 261, 5-45. http://dx.doi.org/10.1016/j.lithos.2015.12.014

Weaver, B. L. (1991). The origin of ocean island basalt endmember compositions: trace element and isotopic constraints. Earth Planetary Science. Letter, 104(2-4), 381-397. https:// doi.org/10.1016/0012-821X(91)90217-6

Whitney, D. L., Evans, B. W. (2010). Abbreviations for names of rock-forming minerals. American Mineralogist, 95(1), 185-187. https://doi.org/10.2138/am.2010.3371

Windley, B. F. (1984). The evolving continents. 2. ed. New Jersey: John Wiley and Sons, 399p.

Zanetti, A., Giovanardi, T., Langone, A., Tiepolo, M., Wu, F.-Y., Dallai, L., Mazzucchelli, M. (2016). Origin and age of zircon-bearing chromitite layers from the Finero phlogopite peridotite (Ivrea-Verbano Zone,Western Alps) and geodynamic consequences. Lithos, 262, 58-74. https:// doi.org/10.1016/j.lithos.2016.06.015

Zanettin, B. (1984). Proposed new classification of volcanic rocks. Episodes, 7, 19-20. 